Thorax 1986;41:737-739

Editorial

\title{
Ocular toxicity from ethambutol
}

Ethambutol is frequently used in Britain, and preliminary results of a recent survey (W Fox, personal communication) have shown that it was prescribed for $85 \%$ of adults with pulmonary tuberculosis. It was given for two months or less in $50 \%$ and for up to three months in another $21 \%$. Dosage was $16 \mathrm{mg} / \mathrm{kg}$ or less in $77 \%$ and $25 \mathrm{mg} / \mathrm{kg}$ in only $8 \%$. Thus most British physicians use ethambutol only for the initial phase of treatment and in the lower doses. Because ocular toxicity is known to be very unusual in these circumstances most physicians do not perform routine eye examinations. This has been confirmed by a survey of 300 consultants in thoracic medicine, made by the Joint Tuberculosis Committee of the British Thoracic Society (unpublished observations). It revealed that routine pretreatment visual acuity tests were made by only $19 \%$ of physicians and that only $9 \%$ use routine visual acuity tests during treatment.

Since ethambutol is used frequently and routine eye tests are rarely used, the statement of the Medical Protection Society in its 1984 report will be of concern to many physicians and their patients. ${ }^{1}$ The report states, "It is wise to make a record of ophthalmic findings, including visual acuity, in each eye, before treatment starts, and at frequent (say monthly) intervals during treatment." The question arises: wise for whom? Is it a wise precaution that may prevent or modify the occurrence of ocular toxicity? Or is it wise as a form of defensive medicine, reducing the chance of successful litigation by a patient in the event of visual disturbance? The Medical Protection Society's experience of British legal practice suggests that a patient developing ethambutol optic neuritis resulting in permanent ocular impairment would receive substantial damages if pretreatment examination of the eyes had been omitted. In Britain the practice of defensive medicine is not usually a major concern of doctors but litigation by patients is becoming more common.

Ethambutol can cause visual impairment as a result of retrobulbar neuritis, which is generally reversible and related to the dose and duration of treatment. Most commonly, the central fibres of the nerve are affected, causing blurring of vision; examination reveals decreased visual acuity, a central or paracentral scotoma, and loss of ability to see green and sometimes red also. A more unusual form of toxicity

Address for reprint requests: Dr KM Citron, Brompton Hospital, London SW3 6HP. affects peripheral optic nerve fibres; this may cause no symptoms but on examination peripheral constriction of the visual field is found. Ethambutol in a dose of $35 \mathrm{mg} / \mathrm{kg}$ or greater has caused optic neuritis in at least $15 \%$ of patients. ${ }^{23}$ The maximum dose now recommended is $25 \mathrm{mg} / \mathrm{kg}$ given daily for two months. If ethambutol is continued for longer, the dose should be reduced to $15 \mathrm{mg} / \mathrm{kg}$.

The table shows the occurrence of ocular toxicity in adults receiving various treatment regimens containing ethambutol. Among a total of 2184 patients ocular toxicity was noted in only 10 , all but one of the cases occurring after the second month. Eight of the cases were detected as a result of routine eye tests. Of these eight cases, only two had symptoms. ${ }^{4-6}$ It is not known whether all patients would have developed symptoms had they continued ethambutol. Ethambutol treatment was limited to the first two months in 928 patients, none of whom manifested symptomatic ocular toxicity. ${ }^{81213}$ The use of six months and nine month regimens for the treatment of pulmonary tuberculosis with ethambutol limited to the initial two months, as recommended by the British Tuberculosis Association for pulmonary tuberculosis, seemed to be safe so far as ocular toxicity was concerned ${ }^{14}$ until the very recent report of a case of what appears to be exceptional idiosyncratic hypersensitivity, in which blindness followed only six days of treatment with ethambutol in a dose of $15 \mathrm{mg} / \mathrm{kg} .{ }^{15}$ In children the incidence of eye toxicity is unestablished and difficult to assess because they may not report visual symptoms and eye testing is problematic. In a study of spinal tuberculosis in Korean children receiving ethambutol in doses of $15-25 \mathrm{mg} / \mathrm{kg}$ for 9-18 months, no evidence of ocular toxicity was obtained despite routine measurements of colour vision, macular threshold, and visual fields. ${ }^{16}$

Ethambutol is removed from the body entirely by excretion through the kidneys. Renal impairment is therefore a contraindication to its use because high blood concentrations may readily produce ocular toxicity. Hence the drug may be hazardous where renal function cannot be readily assessed before treatment, as may occur in some circumstances in developing countries.

What medical purpose do routine eye tests serve? Experience of patients having high doses of ethambutol led to the conclusion that the use of routine visual acuity tests during treatment were not helpful, since they sometimes failed to detect ocular toxicity 
Daily ethambutol regimens and ocular toxicity in adults

\begin{tabular}{|c|c|c|c|c|c|c|c|}
\hline Regimens & $\begin{array}{l}\text { Dose } \\
(\mathrm{mg} / \mathrm{kg})\end{array}$ & $\begin{array}{l}\text { Duration } \\
\text { (months) }\end{array}$ & $\begin{array}{l}\text { Routine } \\
\text { eye tests }\end{array}$ & $\begin{array}{l}\text { No of } \\
\text { patients }\end{array}$ & $\begin{array}{l}\text { Ocular } \\
\text { toxicity } \\
\text { (No of } \\
\text { patients) }\end{array}$ & $\begin{array}{l}\text { Time of } \\
\text { toxicity } \\
\text { (month) }\end{array}$ & Reference \\
\hline $\mathrm{E}$ and reserve drug & 25 & 6 & Yes & 40 & 2 & \multirow{5}{*}{$\begin{array}{l}4,4 \\
4,5 \\
8 \\
2,3 \\
4\end{array}$} & 4 \\
\hline SHE/HE & 15 & 12 & Yes & 99 & 3 & & 5 \\
\hline $\begin{array}{l}\mathrm{E} \text { and other drugs } \\
\text { Initial }\end{array}$ & & & & & & & \\
\hline $\begin{array}{l}\text { Initial } \\
\text { Continutation }\end{array}$ & 25 & 2 & Yes & 304 & 3 & & 6 \\
\hline $\begin{array}{l}\text { Continutation } \\
\mathrm{ER}\end{array}$ & 15 & 22 & & & & & \\
\hline Initial & 25 & 2 & No & 91 & 2 & 7 & 7 \\
\hline Continuation & & 10 & & & & 8 & \\
\hline I SHE/HE & $13-18$ & 12 & No & 300 & 0 & & 8 \\
\hline ESHRZ & & & & & & & \\
\hline Initial & 25 & 2 & No & 105 & 0 & & 9 \\
\hline $\begin{array}{l}\text { Continuation } \\
\text { PRH7 }\end{array}$ & 15 & 2 & & & & & \\
\hline ERHZ & & & & & & & \\
\hline Initial & 25 & 2 & No & 239 & 0 & & 10 \\
\hline $\begin{array}{l}\text { Continuation } \\
\text { ERHZ }\end{array}$ & 15 & 4 & & & & & \\
\hline Initial & 25 & 2 & No & 78 & 0 & & 11 \\
\hline Continuation & 15 & 4 & & & & & \\
\hline ERH & 25 & 2 & No & 286 & 0 & & 12 \\
\hline ERH & 25 & 2 & No & 177 & 0 & & 13 \\
\hline ERHZ & 25 & 2 & No & 164 & 0 & & 13 \\
\hline ERHZ & $16-25$ & 2 & No & 301 & 0 & & 8 \\
\hline
\end{tabular}

E-ethambutol; S-streptomycin; H-isoniazid; R-rifampicin; Z-pyrazinamide.

before symptoms occurred, and might be normal even when symptoms were present. Moreover, a small change in visual acuity might not be the result of ocular toxicity. ${ }^{17}$ Routine tests of colour vision and of peripheral and central fields might be more sensitive than visual acuity, but these elaborate tests are difficult to carry out routinely.

The Joint Tuberculosis Committee has addressed the problem of ethambutol eye toxicity with the advice of an expert ophthalmologist and has proposed the following guidelines.

1 Pre-treatment renal function should be measured by determining serum urea or creatinine concentrations (or both), and ethambutol should be avoided in patients with impaired renal function.

2 The recommended dose and duration of ethambutol treatment should not be exceeded.

3 Any history of eye disease should be recorded in the notes.

4 A pretreatment record of visual acuity should be made by the Snellen test. For those who cannot read, Cambridge low contrast gratings provide a useful alternative. Patients who normally use spectacles for distant vision should be tested wearing these. Ethambutol should not be given to patients with very much reduced visual acuity, who may not notice further minor deterioration of vision.

5 The patient should be told that ethambutol may affect vision and that drugs should be stopped immediately should vision become impaired. To guard against lack of compliance the patient may be assured that this risk is very small.

6 A record should be made in the notes that the patient has been informed about ocular toxicity.

7 The general practitioner should be told that these instructions have been given to the patient.

8 Patients complaining of visual disturbance during chemotherapy should be referred to an ophthalmologist for detailed examination and treatment should be discontinued pending this examination.

9 Routine visual acuity tests during treatment are not recommended.

10 Ethambutol is best avoided in children too young for objective eye tests, and also in adults with language or communication problems that would make assessment difficult.

These recommended procedures are not unduly $\stackrel{\sim}{\sigma}$ complicated or time consuming and are in the interest $N$ of both patient and doctor whenever ethambutol is N given. In the recently reported case of blindness associated with ethambutol treatment ${ }^{15}$ haziness of vision developed on the third day of treatment and irre- $\stackrel{\bullet}{\mathcal{D}}$ versible blindness had developed by the sixth day. This emphasises the need to instruct patients to stop: treatment immediately if visual symptoms are noted rather than wait until the next visit to the clinic to seek advice.

The question of how much is contributed by eth- $\frac{\mathbb{Q}}{2}$ ambutol to the initial intensive phase of chemo-? therapy is currently being investigated by studies in 8 
which pyrazinamide, rifampicin and isoniazid are given without ethambutol or an alternative fourth drug. Should this regimen prove successful it will sound the death knell for the use of ethambutol in Britain.

\section{KENNETH M CITRON \\ Brompton Hospital London SW3}

G O THOMAS

Nevill Hall Hospital

Abergavenny

\section{References}

1 Medical Protection Society. Annual Report and Accounts. No 92. London: Medical Protection Society, 1984:21.

2 Kass I. Chemotherapy regimens used in re-treatment of pulmonary tuberculosis. Part II. Observations on the efficacy of continuation of ethambutol, capreomycin and combined drugs including 4-4 diisoamyloxythiosemicarbamanilide. Tubercle 1965;46:166.

3 Leibold JE. The ocular toxicity of ethambutol and its relation to dose. Ann NY Acad Sci 1966;135:904.

4 Aquinas M, Citron KM. Rifampicin, ethambutol and capreomycin in pulmonary tuberculosis previously treated with both first and second line drugs: the results of 2 years chemotherapy. Tubercle 1972;53: $153-65$.

5 British Medical Research Council. Co-operative controlled trial of a standard regimen of streptomycin PAS and isoniazid, and three alternative regimens of chemotherapy in Britain. Tubercle 1973;54:99-129.

6 Barron GJ, Tepper L, Gino I. Ocular toxicity from ethambutol. Am J Ophthalmol 1974;77:256-60.

7 Hong Kong Tuberculosis Treatment Services, Brompton
Hospital, and British Medical Research Council. A controlled clinical trial of daily and intermittent regimens of rifampicin plus ethambutol in the re-treatment of patients with pulmonary tuberculosis in Hong Kong. Tubercle 1974;55:1-27.

8 Algerian Working Group and British Medical Research Council. Controlled clinical trial comprising a 6 month and a 12 month regimen in the treatment of pulmonary tuberculosis in the Algerian Sahara. Am Rev Respir Dis 1984;129:921-8.

9 Hong Kong and British Medical Research Council. A service programme of anti-tuberculosis chemotherapy with five drugs for four months in the treatment of drug addicts and persons with pulmonary tuberculosis in Hong Kong. Am Rev Respir Dis 1980;122:417-24.

10 Hong Kong and British Medical Research Council. Controlled trial of four thrice-weekly regimens and a daily regimen all given for 6 months for pulmonary tuberculosis. Lancet 1981 ; i:171-4.

11 Hong Kong Chest Service and British Medical Research Council. A service programme with a 6-month intensive chemotherapy regimen in the treatment of drug addicts and prisoners with pulmonary tuberculosis in Hong Kong. Tubercle 1983;64:265-74.

12 British Thoracic Association. Short course chemotherapy in pulmonary tuberculosis. Third report. Lancet 1980;i:1182.

13 British Thoracic Association. A controlled trial of six months chemotherapy in pulmonary tuberculosis. First report. Br J Dis Chest 1981;75:141.

14 British Thoracic Association. A controlled trial of six months chemotherapy in pulmonary tuberculosis. Second report. Am Rev Respir Dis 1982;126:460.

15 Chatterjee VKK, Buchanan DR, Freidmann AI, Green M. Ocular toxicity following ethambutol in standard dosage. Br J Dis Chest 1986;80:288-91.

16 Fox W. Personal communication quoted in Tubercle. 1986;67:27.

17 Citron KM. Ethambutol. A review with special reference to ocular toxicity. Tubercle $1969 ; 50$ (March suppl): 32-6. 